Revised manuscript to be submitted to Brain Research

\title{
Characterization of hippocampal theta rhythm in wild-type mice and glutamate receptor subunit $\delta 2$ mutant mice during eyeblink conditioning with a short trace interval
}

Kanako Takatsuki $^{\mathrm{a}}$, Shigenori Kawahara ${ }^{\mathrm{a}^{*}}$, Masayoshi Mishina ${ }^{\mathrm{b}}$, Yutaka Kirino ${ }^{\mathrm{a}}$

${ }^{a}$ Laboratory of Neurobiophysics, School of Pharmaceutical Sciences, The University of Tokyo, and CREST, Japan Science and Technology Agency, Tokyo 113-0033, Japan.

${ }^{b}$ Department of Molecular Neurobiology and Pharmacology, Graduate School of Medicine, The University of Tokyo, and SORST, Japan Science and Technology Agency, Tokyo 113-0033, Japan.

This manuscript contains 28 text pages and 5 figures.

* Correspondence author. Laboratory of Neurobiophysics, School of Pharmaceutical Sciences, The University of Tokyo, 7-3-1, Hongo, Bunkyo-ku, Tokyo 113-0033, Japan. Tel.: +81-3-5841-4801; Fax: +81-3-5841-4805.

E-mail address: kawahara@mol.f.u-tokyo.ac.jp (S. Kawahara). 


\begin{abstract}
We have shown that glutamate receptor subunit $\delta 2$ (GluR $\delta 2)$ null mutant mice, which have serious morphological and functional deficiencies in the cerebellar cortex, are severely impaired in delay eyeblink conditioning but not in trace eyeblink conditioning, even with a 0 trace interval. Such 0 -trace conditioning does not depend critically on the hippocampus in wild-type mice, but it does in GluR $\delta 2$ mutant mice. Here we examined the hippocampal electroencephalogram (EEG) during 0-trace conditioning in GluR $\delta 2$ mutant and wild-type mice. During the apparatus habituation sessions, the total hippocampal theta activity $(4-12 \mathrm{~Hz})$ of GluR $\delta 2$ mutant mice was less than that of wild-type mice. Activity in the higher frequency band (8-12 Hz, type 1) in GluR $\delta 2$ mutant mice was significantly less than it was in wild-type mice, but activity in the lower frequency band (4-8 Hz, type 2) was not. As learning proceeded during the acquisition sessions, the total theta activity decreased in many of the wild-type mice, while this phenomenon was less prominent in GluR $\delta 2$ mutant mice. Further analysis showed that the type 1 activity in wild-type mice increased in the early sessions and then decreased, while that in GluR $\delta 2$ mutant mice did not change. Type 2 activity tended to decrease in both types of mice as the conditioning proceeded. These results indicate that the distribution of hippocampal EEG frequency and its properties during conditioning are different between wild-type and GluR $\delta 2$ mutant mice, suggesting that the cerebellar cortical dysfunction may cause an alteration in the electrophysiological characteristics of the hippocampus.
\end{abstract}

Theme: Neural basis of behavior

Topic: Learning and Memory: systems and functions - animals

Keywords: Eyeblink conditioning, Hippocampus, Cerebellum, Long-term depression, Mouse, Theta rhythm 


\section{Introduction}

Classical eyeblink conditioning is a useful behavioral model for investigating the neural substrates underlying learning and memory. In this learning, the essential neural circuit has been extensively studied with a delay paradigm, in which the unconditioned stimulus (US) is delayed and terminates simultaneously with the conditioned stimulus (CS). Thompson and his colleagues have indicated that the locus of the memory trace is in the cerebellum; they stress the importance for memory function of long-term depression (LTD) at parallel fiber (PF) - Purkinje cell (PC) synapses in the cerebellar cortex, as well as the presumptive plasticity in the interpositus nucleus (Christian and Thompson, 2003; Kim and Thompson, 1997).

We previously investigated classical eyeblink conditioning in mutant mice lacking the glutamate receptor subunit $\delta 2(\mathrm{GluR} \delta 2)$. GluR $\delta 2$ is selectively expressed in cerebellar PCs (Araki et al., 1993; Lomeli et al., 1993) and within PCs, GluR $\delta 2$ proteins are exclusively localized at PF-PC synapses (Landsend et al., 1997; Takayama et al., 1996). GluR $\delta 2$ mutant mice showed several morphological and functional deficiencies that are restricted to the cerebellar cortex, such as impairments of LTD at PF-PC synapses and PC wiring; they also showed impaired motor coordination (Kashiwabuchi et al., 1995). Consistent with the hypothesis that cerebellar LTD plays a critical role in eyeblink conditioning (Ito, 1989; Thompson and Kim, 1996), GluR $\delta 2$ mutant mice exhibited severe impairment in their learning when a delay paradigm was used (Kishimoto et al., 2001a). However, these mutant mice learned normally in the trace paradigm, in which a stimulus-free trace interval intervenes between the CS and US (Kishimoto et al., 2001a), and even learned normally in the "trace 0 paradigm", in which the US starts just after the CS end (Kishimoto et al., 2001c). These results suggest that another learning mechanism, which does not require the normal functions of the cerebellar cortex (including cerebellar LTD), must be engaged for GluR $\delta 2$ mutant mice to learn in the trace paradigm. Results in another cerebellar LTD-deficient mouse lacking the phospholipase $\mathrm{C} \beta 4$ subunit also support this hypothesis (Kishimoto 
et al., 2001b). Furthermore, we have recently found that ablation of the dorsal hippocampus (Takatsuki et al., 2003), as well as systemic administration of scopolamine (Takatsuki et al., 2002), impairs learning in the trace 0 paradigm in GluR $\delta 2$ mutant mice, but not in wild-type mice. These results clearly indicate that eyeblink conditioning with a short trace interval in GluR $\delta 2$ mutant mice depends largely on the hippocampus, unlike the case in wild-type mice, suggesting that some activity in the functional hippocampus is important for these mutant mice to learn.

Based on this idea, we speculated that there might be some differences in hippocampal activity between wild-type mice and GluR $\delta 2$ mutant mice during eyeblink conditioning in the trace 0 paradigm, although their performances in this paradigm are similar at the behavioral level. Our approach in the present study was to record hippocampal electroencephalographic (EEG) activity from both wild-type mice and GluR $\delta 2$ mutant mice during eyeblink conditioning in the trace 0 paradigm. We analyzed the hippocampal theta rhythm, which is around $4-12 \mathrm{~Hz}$ oscillation and characteristic of a hippocampal EEG. The hippocampal theta rhythm is thought to arise from extracellular currents associated with the activity of local neuronal ensembles, probably hippocampal pyramidal cells (Buzsaki, 2002; Sainsbury, 1998). Numerous studies have suggested that there is a relationship between this theta rhythm and hippocampal-dependent learning (Givens and Olton, 1994; Winson, 1978). Involvement in memory consolidation has also been suggested, because the theta rhythm is present during REM sleep as well as during exploration (Vertes and Kocsis, 1997). It is noted that the hippocampal theta rhythm is subdivided into two types (Bland, 1986; Kramis et al., 1975). One type of theta rhythm is atropine-sensitive (type 2), ranges from 4 to $8 \mathrm{~Hz}$, and emerges when the animal is in behavioral immobility or in an alert state. The other type of theta is atropine-resistant (type 1), ranges from 8 to $12 \mathrm{~Hz}$, and is correlated with type 1 motor movements, such as walking, jumping or rearing. Although these properties of the theta rhythm have primary been investigated in rats, mice also show similar subtypes of the theta rhythm (Ikonen and Tanila, 2001). 
In the present study, we investigated the change in hippocampal theta activity, subdivided into type 1 and type 2, in wild-type and GluR $\delta 2$ mutant mice during eyeblink conditioning. Some of the plausible roles of hippocampal theta rhythms in eyeblink conditioning have already been addressed in both delay and trace paradigms (Berry and Thompson, 1978; Berry and Seager, 2001; Seager et al., 2002; Griffin et al., 2004). Along with these suggested roles, a comparison of the hippocampal theta rhythm in wild-type and GluR $\delta 2$ mutant mice may help us understand the role of the hippocampus in the learning of these mutant mice, which have several deficiencies which affect the cerebellar cortex, including cerebellar LTD. 


\section{Results}

\subsection{Histology}

The loci of the iron deposits were examined after completion of conditioning sessions. The histology confirmed that one of the electrode tips was near the hippocampal fissure, while the other was between the alveus and the CA1 stratum oriens (Fig.2A). Out of 19 wild-type mice and 20 GluR $\delta 2$ mutant mice initially used for the experiment, four wild-type mice and two GluR $\delta 2$ mutant mice were excluded from the final analysis because one of their electrode tips was outside the hippocampus (in the thalamus). The data from the remaining 15 wild-type mice and 18 GluR $\delta 2$ mutant mice were used for the subsequent analysis. Fig.2B shows a typical hippocampal EEG in a wild-type mouse during the habituation sessions. We frequently observed theta frequency oscillation (4-12 Hz), which is characteristic of a hippocampal EEG.

\subsection{Comparison of the hippocampal EEG of wild-type mice and GluR $\delta 2$ mutant mice} during the habituation sessions

First, we examined the differences in the hippocampal EEG of wild-type mice and GluR $\delta 2$ mutant mice when no stimuli were presented. We analyzed the hippocampal EEG during the first habituation session using FFT and the zero-crossing method. FFT allows us to see the relative power of the EEG signal in each frequency band, while the zero-crossing method permits us to see the occurrence of each frequency band component, both relative to the band over 1-20 Hz. Figure 3A shows the average power spectrum of a hippocampal EEG during the habituation session in both wild-type and GluR $\delta 2$ mutant mice. In both groups, there is a large power in the range of 4-12 Hz derived from the hippocampal theta rhythm, but GluR $\delta 2$ mutant mice displayed slightly less total theta power $(4-12 \mathrm{~Hz})$ than wild-type mice. The relative powers of the total theta frequency band were $64.7 \pm 1.2 \%$ in wild-type mice and 58.4 $\pm 1.7 \%$ in GluR $\delta 2$ mutant mice (Fig.3B); a one-way ANOVA revealed that there was a 
significant group effect $\left(F_{1,32}=8.405, P<0.01\right)$. Occurrence of the total theta band was $66.7 \pm 1.2 \%$ in wild-type mice and $62.2 \pm 1.5 \%$ in GluR $\delta 2$ mutant mice (Fig.3C), and there was a significant effect for groups $\left(F_{1,32}=5.312, P<0.05\right)$. These results suggest that total theta activity was less in GluR $\delta 2$ mutant mice than in wild-type mice, in both relative power and in occurrence. In terms of the frequency bands outside the theta range, there were no significant differences in the band higher than $12 \mathrm{~Hz}$ (relative power: $F_{1,32}=0.422, P>0.5$; occurrence: $F_{1,32}=1.308, P>0.2$ ) (Fig.3B and $3 \mathrm{C})$, or in the relative power in the band lower than $4 \mathrm{~Hz}\left(F_{1,32}=2.649, P>0.1\right)$ (Fig.3B). However, there was a significant effect for groups in the occurrence of the frequency band lower than $4 \mathrm{~Hz}\left(F_{1,32}=6.518, P<0.05\right)($ Fig.3C).

When we divided the total theta band into a lower band of 4-8 Hz (type 2) and an upper band of 8-12 Hz (type 1), type 1 activity in GluR $\delta 2$ mutant mice was lower than that in wild-type mice (Fig.3D and 3E). A one-way ANOVA revealed a significant effect for groups (relative power: $F_{1,32}=4.268, P<0.05$; occurrence: $F_{1,32}=12.591$, $P<0.01$ ). There was no significant difference in type 2 activity for groups (relative power: $F_{1,32}=3.470, P>0.05$; occurrence: $\left.F_{1,32}=0.552, P>0.4\right)$. These results indicate that theta activity, especially type 1 activity, is less in GluR $\delta 2$ mutant mice than in wild-type mice.

\subsection{Comparison of the hippocampal theta rhythm in wild-type mice and GluR $\delta 2$} mutant mice during conditioning

As described previously (Kishimoto et al., 2001c), the GluR $\delta 2$ mutant mice learned normally in the trace 0 paradigm (i.e. like the wild-type mice did (Fig.4A)). A two-way repeated measures ANOVA showed no significant interaction effect between sessions and group $\left(F_{6,186}=0.606, P>0.7\right)$, and there was no significant group effect $\left(F_{1,31}=2.248, P>0.1\right)$. We also checked the effects on the basic sensory and motor performance involved in eyeblink conditioning, such as spontaneous eyeblink frequency and startle responses to a tone. The spontaneous eyeblink frequency of 
GluR $\delta 2$ mutant mice was comparable to that of the wild-type mice, and there was no significant effect for groups (one-way ANOVA, $F_{1,31}=0.132, P>0.7$ ). The mean startle responses of the GluR $\delta 2$ mutant mice were also the same as those of the wild-type mice and did not increase during conditioning. There was no significant interaction effect between groups and sessions $\left(F_{6,186}=0.442, P>0.8\right)$, and no significant effects for groups $\left(F_{1,31}=0.005, P>0.9\right)$ or for sessions $\left(F_{6,186}=0.305, P\right.$ $>0.9)$. Learning in trace 0 paradigm, as well as basic sensory and motor performance were normal in these GluR $\delta 2$ mutant mice, as reported previously (Kishimoto et al., $2001 \mathrm{a}, \mathrm{c})$.

Next, we investigated the characteristics of the hippocampal theta rhythm in both wild-type mice and GluR $\delta 2$ mutant mice during eyeblink conditioning in trace 0 paradigm. Figures 4B and 4C show the relative power and the occurrence of the EEG signal, respectively, in the total theta frequency band during conditioning sessions. A two-way repeated measures ANOVA indicated that there was a significant interaction effect between sessions and groups (relative power: $F$ 6, 186 $=3.564, P<0.01$; occurrence: $\left.F_{6,186}=2.450, P<0.05\right)$; the total theta activity of wild-type mice was greater than that of the GluR $\delta 2$ mutant mice from the beginning. A simple main effect test revealed that both the relative power and the occurrence of the EEG signal in the total theta band in GluR $\delta 2$ mutant mice were less than the power and occurrence in wild-type mice on the $1^{\text {st }}$ day $(P<0.05)$ and the $2^{\text {nd }}$ day $(P<0.01)$ of conditioning sessions. As the conditioning progressed, total theta activity tended to decrease in wild-type mice. The simple main effect tests revealed that theta activity was significantly different across sessions in wild-type mice (relative power: $P<0.01$, occurrence: $P<0.01$ ), but such activity was not significantly different across sessions in GluR $\delta 2$ mutant mice (relative power: $P>0.4$, occurrence: $P>0.6$ ). When we looked at the relative power in individual mice, there was a decrease in the relative power of the total theta band in many of wild-type mice (Fig.4D), but that in GluR $\delta 2$ mutant mice showed less change (Fig.4E). 
2.4. Comparison of the 4-8 Hz (type 2) and 8-12 Hz (type 1) theta activity between wild-type mice and GluR $\delta 2$ mutant mice during acquisition sessions

We analyzed type 2 and type 1 theta activity, separately. The relative power of type 2 component in both wild-type mice and GluR $\delta 2$ mutant mice tended to decrease as the conditioning developed (Fig.5A). A two-way repeated measures ANOVA indicated that there was no significant interaction effect between sessions and groups $\left(F_{6,186}=1.194, P>0.3\right)$, but there was a significant effect for sessions $\left(F_{6,186}=3.465\right.$, $P<0.01)$. There was no significant effect for groups $\left(F_{1,31}=0.356, P>0.5\right)$. However, the occurrence of type 2 component was not significantly different across sessions in either wild-type mice or GluR $\delta 2$ mutant mice (Fig.5B). There was no significant interaction effect between sessions and groups $\left(F_{6,186}=0.649, P>0.6\right)$, and no significant effects for sessions $\left(F_{6,186}=1.183, P>0.3\right)$ or for groups $\left(F_{1,31}=0.029, P\right.$ $>0.8$ ). A paired sample $t$-test revealed that there were no significant differences between type 2 activity on the day before conditioning and on the $1^{\text {st }}$ day of conditioning in either wild-type mice or GluR $\delta 2$ mutant mice (relative power: $T_{14}=$ 1.039, $P>0.3$ in wild-type mice, $T_{17}=1.897, P>0.05$ in GluR $\delta 2$ mutant mice; occurrence: $T_{14}=2.115, P>0.05$ in wild-type mice, $T_{17}=0.604, P>0.5$ in GluR $\delta 2$ mutant mice).

On the other hand, type 1 activity increased during the early conditioning sessions in wild-type mice (the $1^{\text {st }}$ and $2^{\text {nd }}$ days of conditioning) (Figs.5C and 5D). A two-way repeated measures ANOVA revealed that there were significant interaction effects between sessions and groups (relative power: $F_{6,186}=4.024, P<0.01$; occurrence: $F_{6}$, $186=5.265, P<0.001)$. A simple main effect test revealed that the relative power of type 1 component in GluR $\delta 2$ mutant mice was lower than that in wild-type mice from the $1^{\text {st }}$ day to the $5^{\text {th }}$ day of conditioning $\left(1^{\text {st }}\right.$ day: $P<0.01,2^{\text {nd }}$ day: $P<0.001,3^{\text {rd }}-5^{\text {th }}$ day: $P<0.05)$. In our analysis using the zero-crossing method, the occurrence of type 1 component in GluR $\delta 2$ mutant mice was lower than that in wild-type mice during all 
conditioning sessions $\left(1^{\text {st }}\right.$ and $2^{\text {nd }}$ day: $P<0.001,3^{\text {rd }}-7^{\text {th }}$ day: $\left.P<0.01\right)$. Furthermore, the paired sample $t$-test between the data on the day before conditioning and the $1^{\text {st }}$ day of conditioning revealed that type 1 activity during the $1^{\text {st }}$ conditioning session was higher than that during the habituation session in wild-type mice (relative power: $T_{14}=$ -2.226, $P<0.05$; occurrence: $\left.T_{14}=-2.720, P<0.05\right)$. In contrast, there were no significant differences between them in GluR $\delta 2$ mutant mice (relative power: $T{ }_{17}=$ -0.666, $P>0.5$; occurrence: $T_{17}=0.483, P>0.6$ ). These results show that type 1 activity in wild-type mice increases in the early phase of conditioning. 


\section{Discussion}

In the present study, we found that the characteristics of the hippocampal theta rhythm were different between wild-type mice and GluR $\delta 2$ mutants in the habituation sessions and through the following conditioning sessions. During the habituation sessions, total theta activity was smaller in GluR $\delta 2$ mutant mice than in wild-type mice. In particular, type 1 activity $(8-12 \mathrm{~Hz})$ was lower in GluR $\delta 2$ mutant mice than in wild-type mice. Though these values are normalized by those over $1-20 \mathrm{~Hz}$, it is possible to say that the spectral pattern of the hippocampal EEG is different between wild-type mice and GluR $\delta 2$ mutant mice. These results are unexpected, because the GluR $\delta 2$ gene is selectively expressed at the dendritic spines of Purkinje cells in wild-type mice (Landsend et al., 1997). Until now, an abnormality in the hippocampal EEG has been reported in mutant mice lacking some genes expressed in the hippocampus (Buhl et al., 2003; Gurevicius et al., 2004). However, we found the abnormality in hippocampal EEG in the mutant mice whose target molecule is not expressed in the hippocampus. We think there are two possible explanations for these results; the deficiency of GluR $\delta 2$ subunit throughout development causes the alteration of function in the hippocampus. This problem is always unavoidable when we are studying conventional knockout mice, and future experiments with conditional knockout mice whose gene-expression is temporally controlled may ultimately provide an answer to this matter. The other possible explanation is that the cerebellar dysfunction itself causes the alteration of function in the hippocampus. It has been reported that other cerebellar mutant mice, lurcher, staggerer and Purkinje cell degeneration (Pcd) mutant mice, exhibit impairment in their spatial learning (Lalonde, 1987; Lalonde et al., 1988; Goodlett et al., 1992). In these studies, the investigators argued that the cerebellum is involved in spatial learning, which requires an intact hippocampus (Morris et al., 1982). Results in the selective destruction of cerebellar Purkinje cells with OX7-saporin in rats also showed impairment in the spatial task without any observable motor deficits (Gandhi et al., 2000), but the impairment in 
lesioned animals was less severe compared to other cerebellar mutant mice. In the present study, since GluR $\delta 2$ mutant mice have ataxia, it is difficult to tell whether the abnormality in the hippocampal EEG is due to an alteration in the context cognition caused by ataxia, or whether it is due to the cerebellar dysfunction itself. But the results obtained in the present study are compatible with the studies described above: all suggest the possibility that the changes in the cerebellar cortex cause the alteration of hippocampal-dependent function.

During conditioning, many of the wild-type mice exhibited a decrease in total theta activity as the learning proceeded, while this phenomenon was less prominent in GluR $\delta 2$ mutant mice. When we divided total theta activity into two bands, a lower 4-8 $\mathrm{Hz}$ (type 2) and an upper 8-12 $\mathrm{Hz}$ band (type 1), type 1 activity in wild-type mice increased in the early phase of conditioning, while it did not change in GluR $\delta 2$ mutant mice. Type 2 activity tended to decrease in both groups as the conditioning proceeded. In wild-type mice, the unchanged total theta activity in the early phase of conditioning probably results from setting off the increase in type 1 activity by the decrease in type 2 activity. The total theta activity decreased as the learning proceeded, and this is thought to reflect the fact that type 1 activity is going back to its spontaneous level and type 2 is decreasing. In GluR $\delta 2$ mutant mice, on the other hand, only the decrease in type 2 activity was observed; there was no change in type 1 activity. The increase in type 1 activity in wild-type mice in the early phase of conditioning does not seem to be relevant to the learning, because there is no significant difference in $\mathrm{CR} \%$ between wild-type mice and GluR $\delta 2$ mutant mice. This is consistent with previous reports (Berger and Thompson, 1978; Berger et al., 1983), which have revealed that an increase in hippocampal firing is observable although delay conditioning does not require a hippocampus (Schmaltz and Theios, 1972). We did not anticipate our finding that type 2 activity decreased during conditioning; we had expected to see an increase in type 2 activity rather than a decrease based on the results in several reports (Berry and Seager, 2001; Olvera-Cortes et al., 2002, 2004). However, there is also a report 
that there were no differences between young and old rabbits in hippocampal theta activity, even though there were differences of acquisition in trace eyeblink conditioning (Woodruff-Pak and Logan, 1988). It remains to be seen what meaning these phenomena have.

Many theories have been advanced to describe the possible role of the hippocampus. These theories include proposals for a role in cognitive mapping (O’Keefe and Nadel, 1978), declarative memory (Squire, 1992), relational memory (Eichenbaum et al., 1992; Eichenbaum, 2001) and configural association (Rudy and Sutherland, 1995). Hippocampal theta rhythm is one of the most prominent features of the hippocampus, and has been speculated to be involved in many functions and behavior, such as memory coding and retrieval (O'Keefe and Recce, 1993; Skaggs et al., 1996), locomotor activities (Vanderwolf, 1969), sensorimotor integration (Bland and Oddie, 2001), working memory (Givens, 1996) and long-term potentiation (Huerta and Lisman, 1995). As we mentioned before, the relationship between hippocampal theta and simple motor learning has also been reviewed (Berry and Seager, 2001). They argued that hippocampal theta, especially the type 2, affects learning rate in the classical eyeblink conditioning. If hippocampal theta is disrupted due to lesions or drugs, the conditioning becomes slower. On the other hand, the conditioning becomes faster if the hippocampal theta is improved by water deprivation. In our present study, type 2 activity tended to decrease in both wild-type and GluR $\delta 2$ mutant mice as the conditioning proceeded. From the viewpoint of the learning-rate hypothesis, the present results might suggest that the hippocampal theta becomes less important as they reach the asymptotic level of the $\mathrm{CR}$, at which point the learning rate does not need to be modulated any longer. However, there still remain some questions: Why did the type 2 not show an increase in the early phase of conditioning? What is the role of the type 1 activities, which showed a different pattern of change during learning? Further investigations on the hippocampal theta rhythm during learning in classical eyeblink conditioning will be necessary to answer this question. 
In conclusion, the present study revealed that theta activity in the hippocampus was different between wild-type mice and GluR $\delta 2$ mutant mice, both in the resting state and during learning. These results indicate that a selective dysfunction of the cerebellar cortex may cause an alteration in the electrophysiological characteristics of the hippocampus in both the resting state and during learning, and suggest an important interaction between the cerebellum and the hippocampus for modulation of the sensorimotor integration that is critical for learning. Further research on the role of the hippocampus using cerebellar mutant mice may lead to the clarification of this cerebellum-hippocampus interaction. 


\section{Experimental Procedure}

\subsection{Subjects and Surgery}

We used 20 GluR $\delta 2^{-/-}$mice with a $99.99 \%$ C57BL/6 genetic background (Kishimoto et al., 2001a) and 19 wild-type C57BL/6 mice (Japan SLC Inc., Hamamatsu, Shizuoka, Japan). After excluding some mice due to their inappropriately positioned electrodes (see the result under Histology for details), the data from 18 GluR $\delta 2$ mutant mice and 15 wild-type mice were used for the analysis. The animals were kept on a $12 \mathrm{~h}$ light/12h dark cycle with ad libitum access to food and water. All experiments were performed in accordance with the guidelines established by the Institutional Animal Investigation Committee at the University of Tokyo and the United States National Institutes of Health Guide for the Care and Use of Laboratory Animals. All efforts were made to optimize comfort and to minimize the number of animals used.

Prior to surgery, the animals were anesthetized with ketamine $(80 \mathrm{mg} / \mathrm{kg}$, i.p., Sankyo, Tokyo, Japan) and xylazine (20 mg/kg, i.p., Bayer, Tokyo, Japan). A pair of twisted Teflon-coated stainless steel wires $(140 \mu \mathrm{m}$ in diameter, No. 7910, A-M Systems, Carlsborg, WA, USA) was chronically implanted in the right dorsal hippocampus. The coordinates of the implants were $1.9 \mathrm{~mm}$ posterior to bregma, 1.5 $\mathrm{mm}$ lateral from the midline, and 1.5-1.7 $\mathrm{mm}$ dorsoventral from bregma. The final depth of the electrode was determined based on the EEG recorded during the implantation. One of the twisted wires was directed at the hippocampal fissure and the other was around the CA1 stratum oriens (their tips were separated by $500 \mu \mathrm{m}$ in depth). Prior to implantation, the electrodes were soldered to the miniature male connector. One stainless steel screw was positioned on the frontal bone and served as a ground electrode. In addition, four Teflon-coated stainless-steel wires (140 $\mu \mathrm{m}$ in diameter) were implanted in the left upper eyelid to record electromyographic (EMG) activity and to deliver a periorbital shock as the US, as described in our previous report (Kishimoto et al., 2001a). These wires were soldered to connector pins, which were 
secured to the skull with dental acrylic resin and stainless steel screws. We administered gentamycin sulfate (4 mg/kg, i.p., Schering-Plough, Osaka, Japan) after the surgery. The mice were allowed to recover for at least 1 week before the experiments began.

\subsection{Conditioning Apparatus}

The conditioning apparatus we used in the present study was the same as that described previously (Takatsuki et al., 2003). In brief, four cylindrical Plexiglas containers were placed in a sound- and light-attenuated chamber and one mouse was placed in each container. The CS was a $350-\mathrm{ms}$ tone $(1 \mathrm{kHz}, 85 \mathrm{~dB})$ and the US was a 100-ms periorbital shock (100 Hz square pulses). In the present study, we used the trace 0 paradigm, in which the US started just after termination of the CS. The CR was monitored through eyelid EMG activity which was band-pass filtered between 0.15 and $1.0 \mathrm{kHz}$ and fed into a computer with sampling rate of $10 \mathrm{kHz}$. EEG activity was band-pass filtered between 0.5 and $30 \mathrm{~Hz}$ and fed into a computer with a sampling rate of $1 \mathrm{kHz}$ using a PowerLab acquisition system (AD Instruments Japan, Nagoya, Japan).

\subsection{Behavioral Procedures}

At least 1 week after the surgery, the animals were given two days to adapt to the experimental apparatus. These habituation sessions were performed in the same way as the conditioning sessions except that no stimuli were presented; EMGs and EEGs were recorded to calculate spontaneous eyeblink frequency and spontaneous hippocampal theta activity, respectively. The conditioning sessions began the next day and continued for 7 days. Prior to daily conditioning, the mice were familiarized with the recording environment for 15 min. Daily sessions consisted of $90 \mathrm{CS}$-US paired trials and 10 CS-alone trials on every 10th trial, with a pseudorandomized intertrial interval of 20-40 s, with a mean of $30 \mathrm{~s}$. The US intensity was carefully calibrated to elicit an 
eyeblink/head-turn response, and adjusted daily for each animal. All experiments were performed during the light phase of the light/dark cycle.

\subsection{Data Analysis}

The EMG signal was processed as described previously (Kishimoto et al., 2001a). Figure 1 shows the EMG raw signal (A), the EMG amplitude (B) and the periods $(a-c)$ for the indices we used in this EMG analysis. First, the EMG amplitude at a given time (Fig. 1B) was calculated from the raw signals (Fig. 1A) as their maximum difference within a 2-ms time window. Then, the mean + SD of the EMG amplitude for $300 \mathrm{~ms}$ before CS onset (period $a$ in Fig.1) in 100 trials was defined as the threshold (horizontal line in Fig.1B), which was then used in the analysis below. In each trial, average values of the EMG amplitude above threshold were calculated for $300 \mathrm{~ms}$ before the CS onset (pre-value, period $a$ in Fig.1), $30 \mathrm{~ms}$ after the CS onset (startle-value, period $b$ in Fig.1), and for $200 \mathrm{~ms}$ before the US onset (CR-value, period $c$ in Fig.1). If both the pre-value and startle-value were less than $10 \%$ of threshold, the trial was regarded as a valid trial. Among the valid trials, a trial was assumed to contain the CR if the CR value was larger than $1 \%$ of threshold and if it exceeded 2 times the pre-value. For the CS-alone trials, the period for CR-value calculation was extended to the end of the CS. To evaluate the effect on the startle response, we calculated the frequency of trials in which the startle-value exceeded $10 \%$ of threshold. To analyze the EEG signal, a Fast Fourier Transformation (FFT) was performed over 0.1-30 Hz. The power of the frequency bands of interest was divided by the power over 1-20 Hz to obtain the "relative power". We analyzed relative power in the $4-12 \mathrm{~Hz}$ theta band (total theta), the lower $4-8 \mathrm{~Hz}$ band (type 2) and the upper 8-12 $\mathrm{Hz}$ band (type 1 ). The division of the theta band was performed as reported previously (Maren et al., 1994). In addition to FFT, we analyzed the EEG signal using a zero-crossing method as reported previously (Asaka et al., 2002). In the zero-crossing analysis, the EEG signal was digitally filtered $(1-20 \mathrm{~Hz})$, and then we measured the time interval between the 
successive crossing of the zero potential recording level, and converted that value to frequency. We used this analysis to obtain the occurrence of the component in each band relative to the band over 1-20 Hz. The frequency of CRs in the valid trials (CR\%), the relative power and the occurrence of the component in those bands of interest were expressed as mean \pm S.E.M. Statistical significance was determined by a one-way ANOVA, a two-way repeated measures ANOVA and a paired sample $t$-test using SPSS statistical software. $P<0.05$ was considered significant in this study.

\subsection{Histology}

After completing all experiments, the mice were deeply anesthetized with sodium pentobarbital. To mark the tip location with iron deposits, an anodal current of $20 \mu \mathrm{A}$ (45 s) was passed through the electrodes. The mice then were perfused transcardially with $0.9 \%$ saline, followed by $10 \%$ formalin containing $10 \%$ potassium ferrocyanide (Wako, Osaka, Japan) to visualize the iron deposits around the electrode tips with Prussian blue reaction. The brains were removed and placed in $10 \%$ formalin. Prior to sectioning, they were placed in a $30 \%$ sucrose solution overnight. Frozen sections (40- $\mu \mathrm{m}$ thick) were made and the loci of the iron deposits were examined under the microscope. 


\section{Acknowledgements}

This work was supported by grants from the Ministry of Education, Culture, Sports, Science and Technology of Japan (\#16390015, \#17209002), the Core Research for Evolution Science and Technology (CREST), and the Solution-Oriented Research for Science and Technology (SORST) of the Japan Science and Technology Agency. K. Takatsuki is a recipient of a Fellowship for Young Scientists from the Japan Society for the Promotion of Science. We are grateful to Dr. I. Ito for technical assistance on the analysis of the EEG signals. 


\section{References}

Araki, K., Meguro, H., Kushiya, E., Takayama, C., Inoue, Y., Mishina, M. (1993)

Selective expression of the glutamate receptor channel $\delta 2$ subunit in cerebellar Purkinje cells, Biochem. Biophys. Res. Commun. 197: 1267-1276.

Asaka, Y., Griffin, A. L., Berry, S. D. (2002) Reversible septal inactivation disrupts hippocampal slow-wave and unit activity and impairs trace conditioning in rabbits (Oryctolagus cuniculus), Behav. Neurosci. 116: 434-442.

Berger, T. W., Thompson, R. F. (1978) Neuronal plasticity in the limbic system during classical conditioning of the rabbit nictitating membrane response. I. The hippocampus, Brain Res. 145: 323-346.

Berger, T. W., Rinaldi, P. C., Weisz, D. J., Thompson, R. F. (1983) Single-unit analysis of different hippocampal cell types during classical conditioning of rabbit nictitating membrane response, J. Neurophysiol. 50: 1197-1219.

Berry, S. D., Thompson, R. F. (1978) Prediction of learning rate from the hippocampal electroencephalogram, Science 200: 1298-1300.

Berry, S. D., Seager, M. A. (2001) Hippocampal theta oscillations and classical conditioning, Neurobiol. Learn. Mem. 76: 298-313.

Bland, B. H. (1986) The physiology and pharmacology of hippocampal formation theta rhythms, Prog. Neurobiol. 26: 1-54.

Bland, B. H., Oddie, S. D. (2001) Theta band oscillation and synchrony in the hippocampal formation and associated structures: the case for its role in sensorimotor 
integration, Behav. Brain Res. 127: 119-136.

Buhl, D. L., Harris, K. D., Hormuzdi, S. G., Monyer, H., Buzsaki, G. (2003) Selective impairment of hippocampal gamma oscillations in connexin-36 knock-out mouse in vivo, J. Neurosci. 23: 1013-1018.

Buzsaki, G. (2002) Theta oscillations in the hippocampus, Neuron 33: 325-340.

Eichenbaum, H., Otto, T., Cohen, N. J. (1992) The hippocampus--what does it do?, Behav. Neural Biol. 57: 2-36.

Eichenbaum, H. (2001) The hippocampus and declarative memory: cognitive mechanisms and neural codes, Behav. Brain Res.127: 199-207.

Christian, K. M., Thompson, R. F. (2003) Neural substrates of eyeblink conditioning: acquisition and retention, Learn. Mem. 10: 427-455.

Gandhi, C. C., Kelly, R. M., Wiley, R. G., Walsh, T. J. (2000) Impaired acquisition of a Morris water maze task following selective destruction of cerebellar purkinje cells with OX7-saporin, Behav. Brain Res. 109: 37-47.

Givens, B., Olton, D. S. (1994) Local modulation of basal forebrain: effects on working and reference memory, J. Neurosci. 14: 3578-3587.

Givens, B. (1996) Stimulus-evoked resetting of the dentate theta rhythm: relation to working memory, Neuroreport 8: 159-163.

Goodlett, C. R., Hamre, K. M., West, J. R. (1992) Dissociation of spatial navigation 
and visual guidance performance in Purkinje cell degeneration (pcd) mutant mice, Behav. Brain Res. 47: 129-141.

Griffin, A. L., Asaka, Y., Darling, R. D., Berry, S. D. (2004) Theta-contingent trial presentation accelerates learning rate and enhances hippocampal plasticity during trace eyeblink conditioning, Behav. Neurosci. 118: 403-411.

Gurevicius, K., Gureviciene, I., Valjakka, A., Schachner, M., Tanila, H. (2004) Enhanced cortical and hippocampal neuronal excitability in mice deficient in the extracellular matrix glycoprotein tenascin-R, Mol. Cell Neurosci. 25: 515-523.

Huerta, P. T., Lisman, J. E. (1995) Bidirectional synaptic plasticity induced by a single burst during cholinergic theta oscillation in CA1 in vitro, Neuron: 1053-1063.

Ikonen, S., Tanila, H. (2001) Effects of metrifonate on the hippocampal theta rhythm of freely moving intact and MS-lesioned mice, Pharmacol. Biochem. Behav. 69: 165-172.

Ito, M. (1989) Long-term depression, Annu. Rev. Neurosci. 12: 85-102.

Kashiwabuchi, N., Ikeda, K., Araki, K., Hirano, T., Shibuki, K., Takayama, C., Inoue, Y., Kutsuwada, T., Yagi, T., Kang, Y., Aizawa, S., Mishina, M. (1995) Impairment of motor coordination, Purkinje cell synapse formation, and cerebellar long-term depression in GluR $\delta 2$ mutant mice, Cell 81: 245-252.

Kim, J. J., Thompson, R. F. (1997) Cerebellar circuits and synaptic mechanisms involved in classical eyeblink conditioning, Trends Neurosci. 20: 177-181.

Kishimoto, Y., Kawahara, S., Suzuki, M., Mori, H., Mishina, M., Kirino, Y. (2001a) 
Classical eyeblink conditioning in glutamate receptor subunit $\delta 2$ mutant mice is impaired in the delay paradigm but not in the trace paradigm, Eur. J. Neurosci. 13: $1249-1253$.

Kishimoto, Y., Hirono, M., Sugiyama, T., Kawahara, S., Nakao, K., Kishio, M., Katsuki, M., Yoshioka, T., Kirino, Y. (2001b) Impaired delay but normal trace eyeblink conditioning in PLC $\beta 4$ mutant mice, Neuroreport 12: 2919-2922.

Kishimoto, Y., Kawahara, S., Fujimichi, R., Mori, H., Mishina, M., Kirino, Y. (2001c) Impairment of eyeblink conditioning in GluR $\delta 2$ mutant mice depends on the temporal overlap between conditioned and unconditioned stimuli, Eur. J. Neurosci. 14: $1515-1521$.

Kramis, R., Vanderwolf, C. H., Bland, B. H. (1975) Two types of hippocampal rhythmical slow activity in both the rabbit and the rat: relations to behavior and effects of atropine, diethyl ether, urethane, and pentobarbital, Exp. Neurol. 49: 58-85.

Lalonde, R. (1987) Exploration and spatial learning in staggerer mutant mice, J. Neurogenet. 4: 285-291.

Lalonde, R., Lamarre, Y., Smith, A. M. (1988) Does the mutant mouse lurcher have deficits in spatially oriented behaviours? Brain Res. 455: 24-30.

Landsend, A. S., Amiry-Moghaddam, M., Matsubara, A., Bergersen, L., Usami, S., Wenthold, R. J., Ottersen, O. P. (1997) Differential localization of $\delta$ glutamate receptors in the rat cerebellum: coexpression with AMPA receptors in parallel fiber-spine synapses and absence from climbing fiber-spine synapses, J. Neurosci. 17: 834-842. 
Lomeli, H., Sprengel, R., Laurie, D. J., Kohr, G., Herb, A., Seeburg, P. H., Wisden, W. (1993) The rat delta-1 and delta-2 subunits extend the excitatory amino acid receptor family, FEBS Lett. 315: 318-322.

Maren, S., DeCola, J. P., Swain, R. A., Fanselow, M. S., Thompson, R. F. (1994) Parallel augmentation of hippocampal long-term potentiation, theta rhythm, and contextual fear conditioning in water-deprived rats, Behav. Neurosci. 108: 44-56.

Morris, R. G. M., Garrud, P., Rawlins, J. N. P., O’Keefe, J. (1982) Place navigation impaired in rats with hippocampal lesions, Nature 297: 681-683.

O'Keefe, J., Nadel, L. (1978) The hippocampus as a cognitive map, Oxford University Press.

O'Keefe, J., Recce, M. L. (1993) Phase relationship between hippocampal place units and the EEG theta rhythm, Hippocampus 3: 317-330.

Olvera-Cortes, E., Cervantes, M., Gonzalez-Burgos, I. (2002) Place-learning, but not cue-learning training, modifies the hippocampal theta rhythm in rats, Brain Res. Bull. 58: $261-270$.

Olvera-Cortes, E., Guevara, M. A., Gonzalez-Burgos, I. (2004) Increase of the hippocampal theta activity in the Morris water maze reflects learning rather than motor activity, Brain Res. Bull. 62: 379-384.

Rudy, J. W., Sutherland, R. J. (1995) Configural association theory and the hippocampal formation: an appraisal and reconfiguration, Hippocampus 5: 375-389. 
Sainsbury, R. S. (1998) Hippocampal theta: a sensory-inhibition theory of function, Neurosci. Biobehav. Rev. 22: 237-241.

Schmaltz, L. W., Theios, J. (1972) Acquisition and extinction of a classically conditioned response in hippocampectomized rabbits (Oryctolagus cuniculus), J. Comp. Physiol. Psychol. 79: 328-333.

Skaggs, W. E., McNaughton, B. L., Wilson, M. A., Barnes, C. A. (1996) Theta phase precession in hippocampal neuronal populations and the compression of temporal sequences, Hippocampus 6: 149-172.

Squire, L. R. (1992) Memory and the hippocampus: a synthesis of findings with rats, monkeys, and humans, Psychol. Rev. 99: 195-231.

Seager, M. A., Johnson, L. D., Chabot, E. S., Asaka, Y., Berry, S. D. (2002) Oscillatory brain states and learning: Impact of hippocampal theta-contingent training, Proc. Natl. Acad. Sci. U. S. A. 99: 1616-1620.

Takatsuki, K., Kawahara, S., Mori, H., Mishina, M., Kirino, Y. (2002) Scopolamine impairs eyeblink conditioning in cerebellar LTD-deficient mice, Neuroreport 13: $159-162$

Takatsuki, K., Kawahara, S., Kotani, S., Fukunaga, S., Mori, H., Mishina, M., Kirino, Y. (2003) The hippocampus plays an important role in eyeblink conditioning with a short trace interval in glutamate receptor subunit $\delta 2$ mutant mice, J. Neurosci. 23: $17-22$. 
Takayama, C., Nakagawa, S., Watanabe, M., Mishina, M., Inoue, Y. (1996) Developmental changes in expression and distribution of the glutamate receptor channel $\delta 2$ subunit according to the Purkinje cell maturation, Dev. Brain Res. 92: $147-155$

Thompson, R. F., Kim, J. J. (1996) Memory systems in the brain and localization of a memory, Proc. Natl. Acad. Sci. U. S. A. 93: 13438-13444.

Vanderwolf, C. H. (1969) Hippocampal electrical activity and voluntary movement in the rat, Electroencephalogr. Clin. Neurophysiol. 26: 407-418.

Vertes, R. P., Kocsis, B. (1997) Brainstem-diencephalo-septohippocampal systems controlling the theta rhythm of the hippocampus, Neuroscience 81: 893-926.

Winson, J. (1978) Loss of hippocampal theta rhythm results in spatial memory deficit in the rat, Science 201: 160-163.

Woodruff-Pak, D. S., Logan, C. G. (1988) No apparent age differences in hippocampal theta frequency in rabbits aged 3-50 months, Compr. Gerontol. A 2: 24-28. 


\section{Figure Legends}

Fig.1. EMG raw signal (A) and EMG amplitude (B) during trial. We calculated the threshold and the pre-value from period $(a)$, the startle-value from period $(b)$ and the CR-value from period $(c)$. The arrowhead in Fig.1B represents the threshold. See the Data Analysis section for details.

Fig.2. (A) Representative photograph of a coronal brain section. The tips of a pair of hippocampal EEG electrodes are indicated by filled triangles. Scale bar, $1 \mathrm{~mm}$. (B) Representative hippocampal EEG in a wild-type mouse. Scale bars, $2 \mathrm{mV}$ and $1 \mathrm{sec}$.

Fig.3. (A) Mean power spectrum of the hippocampal EEG during $1^{\text {st }}$ day of habituation session in wild-type mice (empty circle, $\mathrm{n}=15$ ) and GluR $\delta 2$ mutant mice (filled circle, $\mathrm{n}=18$ ). Error bars indicate SEM. The power of each frequency was normalized to the power over 1-20 Hz (called the "relative power"). (B, C) The relative power (B) and the relative occurrence $(\mathrm{C})$ of component in the frequency band lower than $4 \mathrm{~Hz}$, the band of 4-12 Hz (total theta) and the band higher than $12 \mathrm{~Hz}$, all relative to the activity over 1-20 Hz. The empty bars indicate the data in wild-type mice and the filled bars indicate data in GluR $\delta 2$ mutant mice. A one-way ANOVA comparing the groups revealed the following significant differences: $* P<0.05$, ** $P<0.01$. (D, E) The relative power (D) and the relative occurrence (E) of the component in the lower theta band (4-8 Hz, type 2) and in the upper theta band (8-12 Hz, type 1). A one-way ANOVA comparing the groups revealed the following significant differences: $* P<$ $0.05, * * P<0.01$

Fig.4. (A) Mean CR\% in wild-type mice (empty circle, $\mathrm{n}=15$ ) and GluR $\delta 2$ mutant mice (filled circle, $\mathrm{n}=18$ ). Mice were conditioned using the trace 0 paradigm for 7 days (1-7). sp: spontaneous eyeblink frequency. $(\mathrm{B}, \mathrm{C})$ The relative power (B) and the relative occurrence $(C)$ of component in the band of $4-12 \mathrm{~Hz}$ (total theta) in the $2^{\text {nd }}$ 
habituation session (sp) and during the conditioning sessions. (D, E) The relative power of the total theta band in individual wild-type mice (D) and individual GluR $\delta 2$ mutant mice (E). Each solid line represents the relative power in an individual mouse.

Fig.5. (A, B) The relative power (A) and the relative occurrence (B) of component in the lower theta band (4-8 Hz, type 2$)$ in the $2^{\text {nd }}$ habituation session (sp) and during the conditioning sessions. Empty circles and filled circles represent wild-type mice $(\mathrm{n}=$ $15)$ and GluR $\delta 2$ mutant mice $(n=18)$, respectively. $(C, D)$ The relative power $(C)$ and the relative occurrence (D) in the upper theta band $(8-12 \mathrm{~Hz}$, type 1$)$ in the $2^{\text {nd }}$ habituation session ( $\mathrm{sp}$ ) and during conditioning sessions. 


\section{alveus}

stratum oriens

fissure

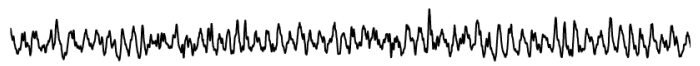



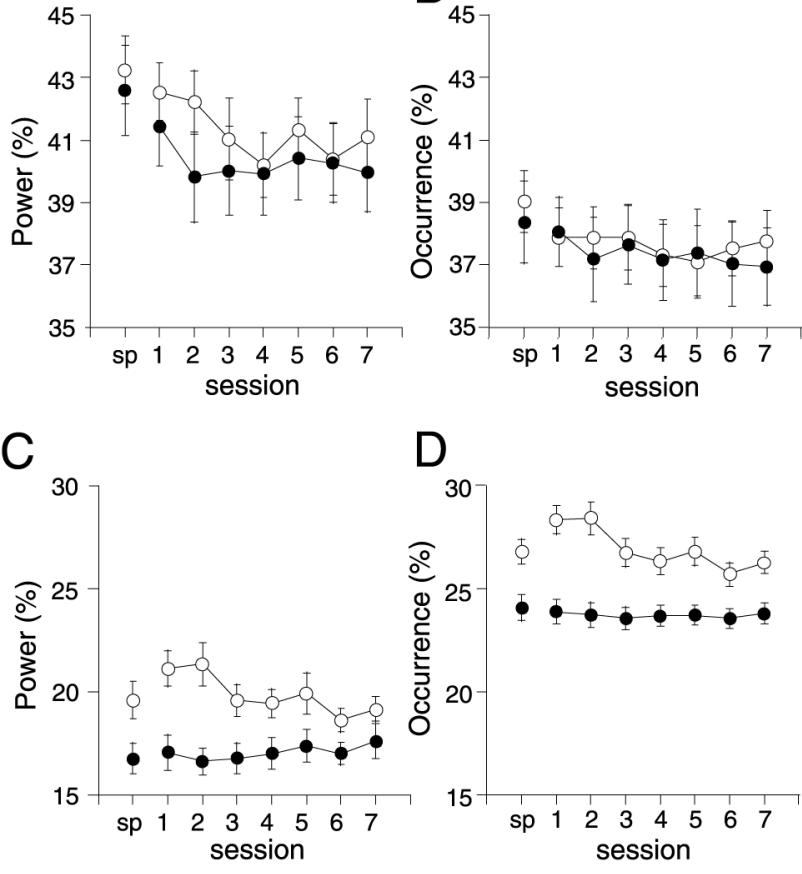